\title{
Emotional skills for entrepreneurial success: the promise of entrepreneurship education and policy
}

\author{
Maha Aly ${ }^{1}$ (D) . David B. Audretsch ${ }^{2,3} \cdot$ Heike Grimm ${ }^{1}$
}

Accepted: 9 June 2021 / Published online: 13 July 2021

(c) The Author(s) 2021

\begin{abstract}
Entrepreneurship education and entrepreneurship policies have a common goal-to spur entrepreneurial activity and its impact on individuals, organizations, regions and countries. Despite the efforts of education and policy in equipping entrepreneurs with the skills, resources and competencies they need to thrive, rich and poignant research in the entrepreneurship literature highlights the daunting emotional challenges confronting entrepreneurs as they traverse the entrepreneurial journey. However, the insights, findings and conclusions from this literature have yet to find their way into providing entrepreneurs with the requisite emotional skills and tools needed to harness the opportunities afforded from entrepreneurship rather than succumb as a victim. This paper analyzes the potential for translational research to develop educational and policy approaches, along with clinical tools, methods and strategies to provide entrepreneurs with the skills and competencies for resilience in an entrepreneurial journey fraught with emotional landmines and challenges.
\end{abstract}

Keywords Entrepreneurship - Emotions - Emotional skills · Entrepreneurship education · Culture $\cdot$ Entrepreneurship policy

JEL Classification L26 $\cdot$ L31 $\cdot$ NGOs

\section{Introduction}

The maxim, "Entrepreneurs are born, not made," prevailed at one time in the field of entrepreneurship. Times change, and so too has the prevalent doctrine about entrepreneurship. No man may be an island, as John Donne ${ }^{1}$ reminded us, and apparently entrepreneurs are people, too, which has spawned the widespread conviction and practice

\footnotetext{
${ }^{1}$ https://en.wikiquote.org/wiki/John_Donne\#: :text=No\%20man\%20is\%20an\%20Island\%2C\%20entire\% 20of\%20itself\%3B\%20every\%20man,I\%20am\%20involved\%20in\%20Mankind\%3B.

Maha Aly

mahamohsenali@gmail.com

1 University of Erfurt, Erfurt, Germany

2 Indiana University, Bloomington, Indiana, USA

3 University of Klagenfurt, Klagenfurt, Austria
} 
that, just as education and training can equip entrepreneurs with the requisite skills and competencies to master the challenges inherent in entrepreneurship, so too can public policy provide the needed resources, influence the entrepreneurial culture and avail external environments conducive to entrepreneurship. Such efforts, however well-meaning, have not always yielded success, resulting in what Lerner (2012) refers to in his seminal book on the failures of public policy to ignite entrepreneurship as The Boulevard of Broken Dreams.

One reason for the often disappointing results resulting from entrepreneurship policy may be that the underlying culture shaping entrepreneurial values remains unaddressed. Inglehart (1997), Hofstede (2001) and Kaasa et al. (2014) suggest that the underlying local, regional, provincial or national culture influence the emotions and beliefs of all inhabitants, including entrepreneurs (Arrak et al., 2020; Calza et al., 2020). Therefore, igniting an entrepreneurial mindset along with the requisite emotional orientation and capabilities may also require a commensurate change in the underlying cultural context to values that are more conducive to entrepreneurship.

The purpose of this paper is to posit that the source of the disappointment and frustration often experienced, despite the best intentions underlying both entrepreneurship education and entrepreneurship policy, is that their common goal-to serve as a catalyst sparking greater entrepreneurial success-may be undermined and thwarted, not so much because of what they actually do, but rather because of what they do not do. In particular, a large and compelling body of research in the field of entrepreneurship highlights the daunting emotional challenges confronting entrepreneurs as they navigate the entrepreneurial journey (Baron et al., 2012; Baum \& Locke, 2004; Cardon et al., 2012; Cardon et al., 2009b; Shepherd, 2003, 2009; Shepherd et al., 2009; Welpe et al., 2012; Williamson et al., 2021). Yet, formal and informal entrepreneurship educational programs have been remarkably taciturn when it comes to addressing the emotional skills and emotional intelligence that would greatly enhance the entrepreneurial journey and ultimately the success of the entrepreneur, even as they have blossomed from their devotion to teaching invaluable operational management knowledge and skills.

While the extant research unequivocally identifies that entrepreneurship is fraught with emotional landmines, there has been virtually no translation into either entrepreneurial education or clinical therapeutic practices. As Williamson (2021, p. 1) pleads, "Let's focus on solutions to entrepreneurial well-being." She goes on to advocate for, "recovery interventions to enhance entrepreneurial well-being" (Williamson, 2021, p. 1). The lack of knowledge spillovers from the foundational research has resulted in a paucity of practices and clinical therapies particularly adapted for and focused on entrepreneurs.

The following section draws on a robust body of research to explain how and why emotions are linked to entrepreneurship. The third section analyzes why the lack of translational research spanning the glaring gap between research and practice has left policy with little guidance on how best to equip entrepreneurs with the emotional tools and competencies needed to harness the opportunities afforded by entrepreneurship, rather than succumb as victims to the emotional turmoil inherent in the entrepreneurial journey. The extant literature may have identified the issues, themes and emotional challenges confronting entrepreneurs; but, as Williamson (2021) emphasizes, it has offered preciously little about what to actually do about them.

Thus, the fourth section explains how and why the emotional concerns of entrepreneurs need to be addressed in order to enhance the efficacy of entrepreneurship policies, along with how public policy can ignite the underlying culture by nurturing the emotional 


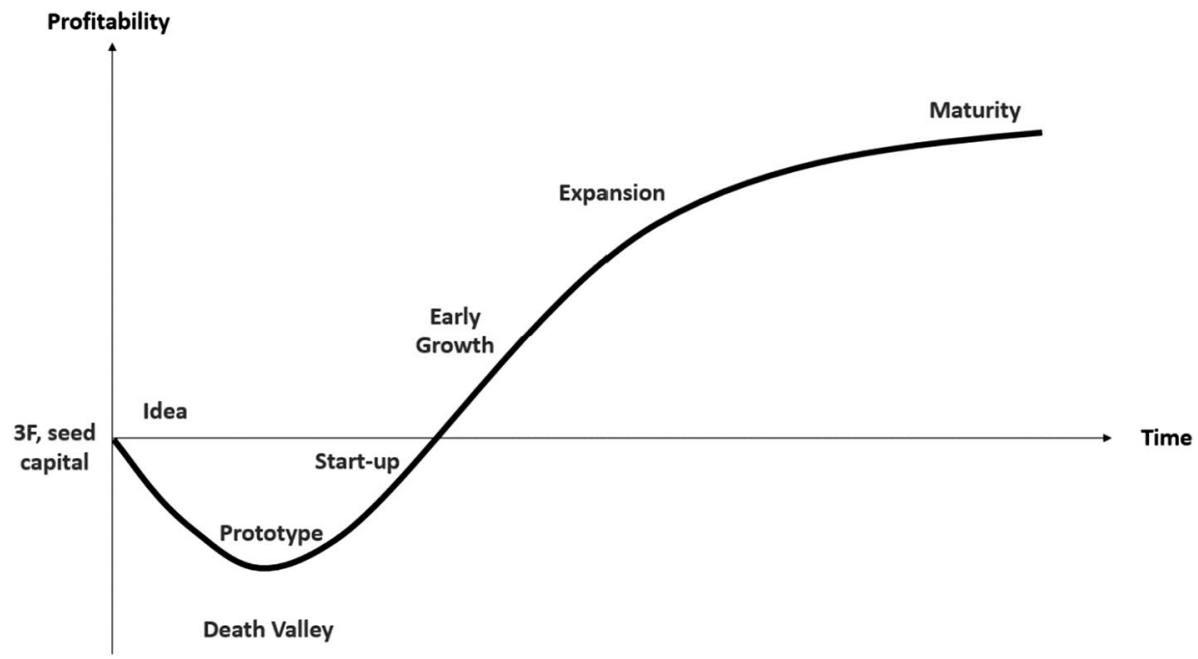

Fig. 1 The J-Curve model of the Entrepreneurial Life Cycle (Love, 2016)

connections embedded in the entrepreneurial eco-system. The fifth section provides a clinical view on future recommendations. A summary and conclusions are provided in the final section. In particular, this paper finds that, until the emotional challenges so adeptly uncovered and analyzed in the extant entrepreneurship literature are actually translated into education, training and policy equipping entrepreneurs with the requisite emotional tools and skills for resilience in the face of daunting emotional challenges and hazards, the promise of entrepreneurship as a catalyst to lift society up, will remain exactly that-a promise.

\section{Emotions and entrepreneurship}

Figure 1 depicts that the well-known and certainly solidly established J-Curve of the startup lifecycle (Love, 2016), viewing that the entrepreneurial journey is fraught with peaks and valleys, ranging from the infamous "valley of death" to the heady heights ensuing from scale-up growth (Auerswald \& Branscomb, 2003). While Fig. 1 characterizes the most salient stages of the journey, it remains silent on the emotional challenges confronting the entrepreneur.

Still, a rich literature has emerged identifying at least some of the emotional states, challenges and trauma experienced by entrepreneurs (Foo, 2011; Patzelt \& Shepherd, 2011; Shepherd et al., 2011; Stroe et al., 2020). The literature linking emotions to entrepreneurship has generally revolved around three different emotional issues or contexts - fear of failure (Brockhaus, 2006; Cacciotti et al., 2016; passion (Breugst et al., 2012; Cardon et al., 2005, 2009a; Mitteness et al., 2012), and trauma triggered by entrepreneurial failure (Shepherd, 2003, 2009, 2017; Shepherd et al., 2009; Ucbasaran et al., 2012; Wolfe \& Shepherd, 2015).

The first issue involves the decision to become an entrepreneur. Perhaps the most salient characteristic of entrepreneurs, identified both in the scholarly literature but also prevalent in the broader societal notion of what makes entrepreneurs distinct and different, is their 
lower aversion to risk in making decisions (Brockhaus, 2006; Kerr et al., 2019). As noted in Forbes, "Successful entrepreneurs need to be calculated risk takers".

A large and compelling body of research has identified a plethora of sources of risk inherent in entrepreneurship, such as bankruptcy, suffering a loss of reputation, strategic challenges, financial devastation, volatility of technology, and political and economic turbulence, "For entrepreneurs, risk is part of the process. Starting a new business and working to achieve success creates difficult situations and unique obstacles that entrepreneurs must overcome. From the beginning, entrepreneurs must take risks that could jeopardize their finances, health, and stability. Taking calculated risks is an essential part of the entrepreneurial journey". 3

Kerr et al. (2019) find that the entrepreneurs have a greater propensity for incurring risk than do their non-entrepreneur counterparts. Still, there are two sides to the coin of lower risk aversion. It is one thing to undertake risky entrepreneurial ventures. It is another not to have an emotional response when confronted by elevated risky situations. According to Cacciotti et al. (2016), the emotional response of fear when confronted with an elevated likelihood of failure can adversely influence decision-making and outcomes for entrepreneurs. In addition, Cacciotti et al. (2016, p. 302) characterize fear of failure as a "temporary emotional experience."

Patzelt and Shepherd (2011) point out that positive emotions, including passion, excitement, happiness, satisfaction, and flow (Barrett et al., 2007) have been found to be positively related to people who are self-employed. However, they also point to research documenting what they term as the "dark side of entrepreneurship," in that "the self-employed may be more susceptible than employees to negative emotions such as stress, fear of failure, loneliness, mental strain, and grief".

A different strand of the literature, dating back to the insight of Knight (1921), in his seminal treatise on Risk and Uncertainty, shifts the focus away from risk to uncertainty. Risk generally characterizes decisions where the likelihoods of known outcomes are also known. By contrast, uncertainty characterizes decisions where the outcomes ensuing from decisions are not known, rendering it impossible to assign a probability distribution associated with those (unknown) outcomes. Alvarez (2005) and Alvarez and Barney (2005, 2007) posit that making decisions and acting under conditions of uncertainty are what bestow entrepreneurs with their competitive advantage. McMullen and Shepherd (2006) similarly identify the willingness to work and live under conditions of uncertainty as a key characteristic which distinguishes entrepreneurs from their non-entrepreneur counterparts.

A very different strand of the literature directly focuses on the emotions incurred by entrepreneurs when they experience failure. Shepherd (2003), for example, draws on methods from the discipline of psychology on grief to analyze how entrepreneurial failure elicits the negative emotional response of grief. Such emotional trauma impedes the ability of (failed) entrepreneurs to learn from their experience with entrepreneurial failure and move forward in an emotionally healthy manner. Ucbasaran et al. (2013, p. 163) similarly found that entrepreneurship is "fraught with psychological, social, and financial turmoil", which incur substantial health costs (emotional and psychosomatic) on entrepreneurs.

\footnotetext{
${ }^{2}$ Chris Caroza, "Why Successful Entrepreneurs Need to be Calculated Risk Takers," Forbes, August 7 , 2020, accessed on April 15, 2021 at https:/www.forbes.com/sites/chriscarosa/2020/08/07/why-successfulentrepreneurs-need-to-be-calculated-risk-takers/?sh=e9b95372f5b1.

3 Destry Witt, “The Risk of Entrepreneurship," Thrive Global, May 30, 2019, accessed on April 15, 2021 at https://thriveglobal.com/stories/the-role-of-risk-in-entrepreneurship/.
} 


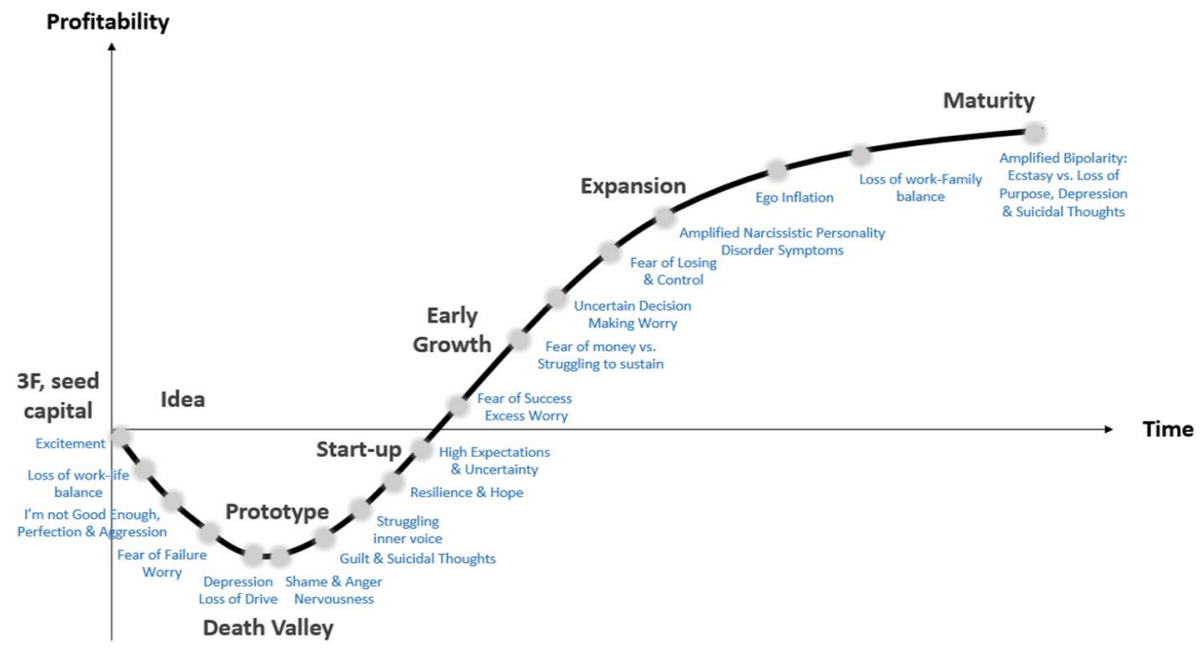

Fig. 2 A clinical view: major emotional challenges along entrepreneurial phases. Aadapted from the J-Curve (Love, 2016)

The emotions involved in the entrepreneurial journey have been the direct focus by Cardon et al., (2012, p. 1), who define entrepreneurial emotion as "the affect, emotions, moods, and/or feelings - of individuals or a collective - that are antecedent to, concurrent with, and/or a consequence of, the entrepreneurial process, meaning the recognition/creation, evaluation, reformulation, and/or the exploitation of a possible opportunity".

Similarly, Welpe et al. (2012) analyze specific emotions elicited in entrepreneurship. In particular, they found that the propensity for an entrepreneur to commercialize an opportunity through entrepreneurship is enhanced by the emotions of joy and anger, which could be viewed as bipolar emotional congestion. By contrast, the emotion of fear tends to suppress the propensity for an entrepreneur to commercialize an opportunity through entrepreneurship. Breugst et al. (2012) find that the emotion of passion by an entrepreneur enhances the commitment of employees in entrepreneurial ventures. Stroe et al. (2020) provide compelling empirical evidence suggesting that the emotion of passion can moderate the fear of failure in entrepreneurs. As example of how culture embeds the emotion "fear of failure", sometimes stems from policy or regulatory systems. Audretsch and Lehmann (2016) point out in their book "The Seven Secrets of Germany", the legal and societal penalties entrepreneurs in Germany are incur if they fail:

Failed entrepreneurs in Germany simply did not get a second chance. Germany, like many of its European neighbors, has treated honest but insolvent entrepreneurs more or less like fraudulent criminals. (...) In Germany, failed entrepreneurs could expect to take six years in order to get a fresh start (...). There are other dire consequences confronting bankrupt entrepreneurs as well.

Even if such legal regulations are currently not that harsh, they may still have their impact on the German culture and people, who, according to many studies, are risk averse and uncertainty avoidant (Audretsch, 2017; Stuetzer et al., 2018).

Thus, a broad spectrum of research has concluded that entrepreneurs are not invulnerable to emotional volatility in general, and negative as well as positive emotions over 
the entrepreneurial journey (Baron, 2008; Bernoster et al., 2018; Foo et al., 2009). This rich literature has made it undeniable that the emotional state of entrepreneurs is not neutral but rather strongly influenced by the circumstances and context. Emotions typically accompanying the entrepreneurial journey are aligned to the standard entrepreneurial life cycle in Fig. 2. In contrast, to Fig. 1, which depicts emotional neutrality with respect to the life cycle stage, Fig. 2 provides a road map of some of the typical emotional states confronting entrepreneurs as they traverse the entrepreneurial journey. Examples of emotional challenges that could confront entrepreneurs in the startup and earliest phase of the entrepreneurial journey include self-doubt, feeling not good enough, fear of failure, excess worry, loss of work-life balance, feeling not in control and a high degree of nervousness or aggression.

The emotional challenges confronting entrepreneurs in the stage of the "Death Valley", could rise to depression, loss of intrinsic drive, shame, guilt, anger, feeling of huge loss, loneliness, self-doubt and even more. As the entrepreneur develops their venture into the growth and early expansion stages, they may experience emotional challenges such as fear of success, fear of money or of being rich, fear of losing control, ego inflation, and hope mixed with excess worry. The worst of all is reacting emotionally to the emotional challenges, where an entrepreneur might feel the fear of failure, and then project this emotion inwards by feeling angry at themselves due to this fear.

Thus, while a compelling literature has made it clear that emotions, spanning from euphoria to despair, are anything but neutral, it is remarkably silent on exactly what needs to be done to enable entrepreneurs to better deal with and harness their emotions as they traverse across the entrepreneurial journey. Despite the few voices calling not just for more research identifying and characterizing the links between emotions and entrepreneurship but also solutions to give flesh and blood entrepreneurs the tools they need to best deal with their emotional challenges (Shepherd, 2017; Williamson, 2021), little has actually been developed to guide educational and clinical practice. The emotional challenges depicted for each entrepreneurial stage in Fig. 2 need to be addressed clinically. An important way to provide the translation from the robust research in the entrepreneurship literature to actually providing assistance and support for those entrepreneurs burdened by such emotional challenges is through clinical therapies and practices to enhance the prospects for entrepreneurial success. Business coaching, at least in the traditional and widely accepted sense, is simply not enough.

\section{Translating the research into clinical practice}

As Shepherd (2017) and Williamson (2021) point out, entrepreneurship education, training and guidance is scarce for entrepreneurs either preparing for their journey or else confronted by the emotional challenges, which the robust literature covered in the previous section has identified as inherent and prevalent in traversing that journey. For example, the MIT program in entrepreneurship education offers the standard courses focusing on finance, marketing, law, leadership, marketing and planning, operations and strategy. ${ }^{4}$ Despite the plea by Shepherd (2003), who advocated that the compelling research

\footnotetext{
4 “MIT Entrepreneurship Courses Arranged by Topic," accessed on April 16, 2021 at https://ocw.mit.edu/ courses/entrepreneurship/topic-list/.
} 
identifying the extent and consequences of emotional trauma suffered from entrepreneurial failure needs to be translated into entrepreneurship education, the entrepreneurship curriculum at MIT, as elsewhere, remains decidedly silent.

The linear model of innovation may have been debunked by Stokes (1997) in his seminal book, Pasteur's Quadrant. However, the kernel of the linear model of innovation, as many have claimed was posited by Bush (1945) still provides a useful framework for linking basic research to applied research, development, innovation and ultimately commercialization and diffusion. To traverse the arc of the linear model of innovation requires the translation from basic and applied research to the actual application required by innovation and commercialization.

In terms of the field of entrepreneurship, foundational research in finance has been translated to the context for actual entrepreneurs in the field of entrepreneurial finance and the corresponding courses. Similarly, foundational research in marketing has been translated to the context for actual entrepreneurs in the field of entrepreneurship marketing and corresponding courses. Analogous translational fields for entrepreneurship have been developed and taught for a score of other key topics, ranging from law to leadership, accounting, planning, operations and to strategy. However, no analogous translational field for emotional skills for entrepreneurship exists, leaving entrepreneurs in the lurch to fend for themselves, despite a compelling body of research documenting the daunting emotional challenges confronting entrepreneurs throughout their entrepreneurial journey.

While research has succeeded in identifying and analyzing the impact on emotions triggered by various stages of the entrepreneurial journey, as depicted in Fig. 2, as Shepherd (2017) and Williamson (2021) point out, it has been remarkably silent on (1) educational and clinical approaches to equip entrepreneurs with greatly needed emotional skills and competencies and (2) what the response of actual (including nascent) entrepreneurs are to specific types of emotional education and training, along with particular types of clinical approaches and tools for instilling emotional skills and competencies that could potentially enhance entrepreneurial performance and the prospects for positive and successful entrepreneurial outcomes.

It is not only the sphere of education that is concerned with entrepreneurial skills and competencies. In addition, public policy generally has a mandate to ignite entrepreneurship. Thus, to address the glaring gap between basic research on entrepreneurial emotional challenges and actually providing solutions to address the problem requires new approaches in the realm of both education as well as public policy. While the former involves new dimensions and aspects for teaching and training, the latter has more of a focus on formal institutions and policy instruments to render an underlying culture context more conducive to entrepreneurship. Such policy instruments might range from revisiting the legal regulations imposing barriers to entrepreneurship, to providing training programs to open the inherited mindset, beliefs and cultural values and practices to embracing rather than denouncing the spirit of entrepreneurship.

For example, the cultural value of "uncertainty avoidance" has received considerable attention as a deterrent of entrepreneurship. The underlying meta-meaning needs not to be restricted to the negative emotions of fear or insecurity, however, but can instead be reframed as adventure, development, discovering new opportunities or growth outside the comfort zone.

A second example is provided by the cultural practice of "failure avoidance", where failure results in stigma and damages the ego of entrepreneurs (Landier, 2005; Simmons et al., 2014). From a clinical perspective, accepting failure and dealing with it as a normal part of the entrepreneurial process, not to mention life, that can naturally happen to all 
entrepreneurs provides entrepreneurs with the emotional skills to develop higher resilience, which in turn will enhance their entrepreneurial success. Educating society that failure is not a shameful stigma is essential to enabling entrepreneurs to dare to remain in their home locations, rather than fleeing to regions and cities with a culture tolerating failure, such as Silicon Valley, with its famous brand, "Fail Early, Fail Fast".

Thus, the field of entrepreneurship is replete with attendant arguments focusing on, as well as characterizing and analyzing, at least some of the emotional responses and conditions attendant to entrepreneurship. What is glaringly absent, however, is the requisite concomitant translational research upon which to base emotional education and training, as well as clinical therapeutic approaches to enhance the entrepreneurial experience and ultimately the resulting entrepreneurial performance.

The absence of such translational research providing the requisite linkages between basic and applied research on the emotional challenges confronting entrepreneurs and how best to bestow resilience is particularly problematic due to the unique but also very wide range of diverse entrepreneurial contexts. Just as Welter (2011) and Welter et al. (2019) emphasize that entrepreneurship is shaped by its underlying context, so too are the emotional challenges confronting entrepreneurs likely to be colored by the entrepreneurial context.

For starters, the occupational context of entrepreneurship is decidedly distinct. A growing body of studies (Brandstätter, 2011; Obschonka \& Stuetzer, 2017; Obschonka et al., 2015; Stuetzer et al., 2016; Zhao \& Seibert, 2006) has found that the personalities of entrepreneurs are decidedly distinct from the non-entrepreneur counterparts. In particular, an analysis of the Big Five personality characteristics (Jang et al., 1996; John \& Srivastava, 1999; Loehlin et al., 1998; Magnusson \& Torestad, 1993) reveals that, in comparison to non-entrepreneurs, entrepreneurs have a greater propensity to be extraverted, conscientious and open, but a lower propensity to be agreeable and neurotic (Stuetzer et al., 2016; Tavassoli et al., 2021; Obschonka et al., 2015; and Obschonka \& Stuetzer, 2017).

The entrepreneurial difference may be, at least partially, attributable to the underlying genetic makeup of entrepreneurs (Koellinger et al., 2010). Rietveld, (2020) suggest that the search for a unique genetic variant distinguishing entrepreneur remains elusive, but still promising. Koellinger et al. (2010) suggest that the answer to the most fundamental question in the field of entrepreneurship as to why some people choose to become entrepreneurs, while others do not, lies in the genetic makeup.

In addition, the geographic, institutional, national, ecosystem, industry and temporal contexts have all been found to influence entrepreneurship, as have individual specific characteristics, such as age, experience, gender, social capital, ethnicity, nationality, religion and immigrant status (Audretsch, 2007; Audretsch et al., 2006; Gilbert, 2006). In terms of education and training, it may be wrong to assume that a singular approach would be effective for all these diverse and heterogeneous contexts and types of people (Singla et al., 2018). Similarly, in terms of clinical approaches to bestowing entrepreneurs with the requisite emotional tools and competencies for emotional resilience throughout the entrepreneurial journey, the assumption of a singular clinical approach may be equally erroneous.

A plethora of approaches for education and clinical practices for emotional skills and competencies are available (American Psychiatric Association, 2013; Singla et al., 2018). Equally important, a broad and diverse range of approaches for education and clinical practices has been developed for specific contexts, ranging from athletics to executives, families, human resource management and criminology. But not, most strikingly, for entrepreneurs (Shepherd, 2017; Williamson, 2021). It is as if entrepreneurs are devoid of emotional challenges. However, this claim flies in the face of the highly compelling research showing 
exactly the opposite- the entrepreneurial journey is fraught with emotional landmines and hazards, as well as peaks and valleys. Thus, it is not the basic research linking emotions to entrepreneurship that is lacking, but rather the applied clinical research and practices available for entrepreneurs - what to do about the emotional challenges inherent in entrepreneurship and how they can best be addressed and mitigated.

For example, Hatak et al. (2020) find that ADHD symptoms are related to the mental health of entrepreneurs, as well as entrepreneurial performance. However, they also find that the actual impacts of ADHD on mental health of entrepreneurial performance are influenced by the extent to which the entrepreneur is passionate about their entrepreneurial venture. While the findings of Hatak et al. (2020), along with Antshel (2018), make an invaluable contribution to identifying the links between emotions and entrepreneurship, they offer little in terms of clinical prognosis. They presumably leave that for others. The problem is, there are no "others". There is simply no or little translational research identifying the appropriate educational and clinical responses and treatments to a very real emotional challenge experienced by entrepreneurs.

Shepherd (2004, p. 274) makes a compelling plea for such translational research that would result in clinical and educational practices for the specific context of entrepreneurs, "As theory develops and increases our understanding of the role of emotion in learning from failure, entrepreneurship educators have the opportunity to reflect these advancements in their pedagogies. This requires a focus on how students "feel" rather than on how, or what, they "think". Shepherd (2004, p. 174) goes on to propose "suggested changes to pedagogy to help students manage the emotions of learning from failure and discuss some of the challenges associated with measuring the implications of these proposed changes". Such pedagogical changes focusing on the emotional challenges confronting entrepreneurs over their entrepreneurial journey focuses on "educating students on how to manage their emotions to avoid failure and, more generally, improve their emotional intelligence and for organizations to improve their ability to help individuals regulate their emotions" (Shepherd, 2004, p. 180). A welcome pathbreaking study by Williamson et al. (2021) goes beyond determining entrepreneurship induces stress, and negatively impacts health, by suggesting helpful practices that can be implemented to mitigate the deleterious affect of stress on entrepreneurs.

A multitude of clinical interventions and techniques are available to and practiced in therapy to address emotional health. ${ }^{5}$ Singla et al., $(2018,226)$ point out that with, "stress, anxiety, and depression at epidemic levels across the world, therapy has become more commonplace". They go on to emphasize that "Therapy is available in schools, hospitals, and even churches".

The broad range of therapeutic techniques and tools available and pervasive in clinical practice lies beyond the scope of this paper (American Psychiatric Association, 2013). Suffice to mention and highlight several of the more commonly used therapeutic techniques used in dealing with emotional stress and turmoil—solution focused therapy, open ended therapy, acceptance and commitment therapy, cognitive behavioral therapy, dialectical behavioral therapy, positive psychotherapy (American Psychiatric Association, 2013), post-traumatic stress growth healing (PTSG), bipolar integration, and inner child trauma healing. However, the appropriate and most effective therapeutic approach is shaped to a large extent by the context and case. The context here involves not just an entrepreneur,

\footnotetext{
5 Kelly Miller, "23 Therapy Interventions and Techniques to Apply Today,” Positive Psychology, February 22, 2021, accessed on April 14, 2021 at https://positivepsychology.com/therapy-interventions-techniques/.
} 
compared to, say, a child, athlete or airline pilot, but also the various entrepreneurial contexts and entrepreneur specific characteristics previously discussed, such as industry, culture, religion, region, age, gender, etc. Thus, while there are general and widely accepted clinical and therapeutic techniques and tools, developing and applying them for the specific entrepreneurial context would not only close the gap separating research from clinical practice and education, but it would also surely contribute to enhancing entrepreneurial success.

\section{Policy implications}

In her call for a mandate for public policy to promote entrepreneurship, Grimm refers to entrepreneurs as, Local Heroes in the Global Village (Audretsch et al., 2005). Her point is that entrepreneurship provides a platform to take advantage of the opportunities accruing from globalization, rather than falling as a victim from globalization in particular (Grimm, 2006, 2009). She uncovers a score of impediments systematically hindering entrepreneurial activity and therefore calls for robust and decisive public policies to ignite entrepreneurship (Grimm, 2006).

As Grimm $(2009,2011)$ points out, the mandate for entrepreneurship policy emerged from research highlighting the key role played by entrepreneurship as a catalyst for economic performance. Those cities, regions, provinces and countries with higher rates of entrepreneurship also exhibit higher rates of economic growth and employment creation (Audretsch \& Keilbach, 2004; Audretsch \& Lehmann, 2005; Audretsch et al., 2006, 2008). According to Grimm (2011, p. 1526), "With the Lisbon Strategy and mandate, the European Commission committed itself to promoting entrepreneurship as a major driver of innovation, competitiveness, and growth".

It was not just the European Commission that prioritized entrepreneurship policy as a strategy for igniting economic performance. As Grimm (2006 and 2004) makes clear, public policy, ranging from cities to regions, provinces, states and entire countries, looked to entrepreneurship as the remedy for economic and social stagnation. However, looking was not enough. Even as thought leaders in policy and business realized that robust entrepreneurial activity serves as a key catalyst driving economic growth and employment creation, they also discovered a lack of policy instruments to spur entrepreneurship. Left to themselves, or perhaps more accurately said, left with the market imperfections of imperfect and asymmetric information and inability to compensate for inadequate or missing networks and their formidable externalities, the propensity for people to become, remain and thrive as entrepreneurs was simply inadequate in many local, regional, state and national contexts (Audretsch, 2007; Audretsch et al., 2006).

Policy responded to the tepid entrepreneurial activity by developing and introducing a plethora of new instruments designed to ignite entrepreneurship (Audretsch, 2007). Returning to Fig. 1, friends, family and fools did not always provide adequate funding meeting the needs of entrepreneurs in the earliest stages of the entrepreneurial journey. Public policy tried to fill this liquidity gap by offering various lending and grant programs for startups and new ventures at the earliest stages (Acs et al., 2016). To address the sometimes glaringly deficient managerial capabilities of nascent (would-be) entrepreneurs, a host of programs were offered to instill business plan, accounting, finance and human resource skills.

As entrepreneurial startups evolved along the arc of their journey, new problems and challenges arose-in particular, the dreaded valley of death (Audretsch, 2007; Auerswald 
\& Branscomb, 2003; Wessner, 2008). To enable entrepreneurs to safely traverse the "valley of death," new policy instruments were needed, such as the United States Small Business Innovation Research Program (SBIR), which required federal agencies to allocate a certain percentage of their procurement budgets to small business. A robust literature has found that the SBIR has generally succeeded in enabling entrepreneurs and their startups to safely forge the valley of death (Link \& Scott, 2010, 2012; Wessner, 2008). To provide the requisite research and technologies fueling innovative activity for entrepreneurs as they scaled up, universities developed their technology transfer offices, made possible by the Bayh-Dole Act (Aldridge \& Audretsch, 2011; Gores and Link, 2021; Mowery et al., 2004), to facilitate technology transfer and knowledge spillovers to entrepreneurial businesses (Hülsbeck \& Lehmann, 2007; Hülsbeck et al., 2013; Lehmann \& Starnecker, 2012; Siegel $\&$ Link, 2005; Siegel et al., 2003). Still, the main focus of the new policy instruments to spur entrepreneurship revolved around the more mundane, but pressing needs of entrepreneurs-finance, assistance with taxes, regulatory burden, zoning, hiring and managing employees, to name just a few (Audretsch, 2015). In some places, the new entrepreneurship policies took hold and the economic performance flourished (Audretsch, 2007, 2015). Gordon Moore, founder of Intel, made it seem easy, "Combine liberal amounts of technology, entrepreneurs, capital, and sunshine. Add one (1) University. Stir vigorously". 6

Most notably, cities such as Austin, Berlin, Oxford, Madison, and regions such as the Research Triangle in North Carolina and Northern Virginia outside of Washington, D.C. celebrated their newfound prosperity ushered in by vibrant entrepreneurship (Link, 1995). Entire countries, such as Israel, which became branded as the Start-up Nation, thrived with dynamic economies propelled by vigorous entrepreneurial activity (Senor \& Singer, 2011).

But not all places. While the great entrepreneurial cities and regions, such as Silicon Valley in California, and Route 128 around Boston (Saxenian, 1994) grabbed the headlines as well as riveted the attention of both scholars and thought leaders in policy and business (Bresnahan \& Gambardella, 2004), far from the headlines was the less explosive or even alarmingly tepid entrepreneurial response to the extensive efforts by public policy to ignite entrepreneurship (Acs et al, 2016). The failure of entrepreneurship to take root was not restricted to the most visible disappointments, such as Detroit and Gary, Indiana. For example, the former Minister of Science, Research and the Arts in the Bundesland of Thuringia, as well as former candidate for the Presidency of the Federal Republic of Germany, Dagmar Schipanski, reported on the broad range of policies that had failed to ignite entrepreneurship and ultimately growth and prosperity in Thuringia, "We tried that. It didn't work". ${ }^{7}$ Entire countries expressed frustration at the tepid entrepreneurial response to well-meaning policies to ignite entrepreneurship (Aly \& Galal-Edeen, 2020). Joschka Fischer, an early member of the Green Party, who subsequently was appointed by Chancellor Gerhard Schroeder to serve as Minister of Foreign Affairs, lamented, "A company like Microsoft would never have a chance in Germany". ${ }^{\circ}$

The inability of policies to ignite entrepreneurship has been documented in Lerner's (2012) prize winning book, Boulevard of Broken Dreams: Why Public Efforts to Boost Entrepreneurship and Venture Capital Have Failed. The Broken Dreams highlighted in Lerner's title graphically describe the disappointment and frustration, not to mention

\footnotetext{
${ }^{6}$ Cited from Bresnahan and Gambardella (2004).

7 Personal communication with David Audretsch at the Max Planck Institute of Economics in Jena, Germany in 2005.

8 “Those German Banks and Their Industrial Treasures," The Economist, January 21, 1995, 75-76.
} 
taxpayer's money, squandered in public efforts to spur entrepreneurship. A large body of research, spanning a broad range of local, regional, national and institutional contexts reaches the same remarkably singular conclusions-policies to ignite entrepreneurship simply do not work (Lerner, 2012; Bresnahan \& Gambardella, 2004; Acs et al., 2016). As Lerner (2012) warns, "Silicon Valley, Singapore, Tel Aviv-the global hubs of entrepreneurial activity all bear the marks of government investment. However, for every successful public intervention spurring entrepreneurial activity, there are many failed efforts, wasting untold billions in taxpayer dollars".

It may be that the disappointment and frustration with entrepreneurship policies around the globe to produce the intended results lies less with an inherit inability for public policy to be effective and more about the mismatch between policy strategies and specific instruments, on the one hand, and the bottlenecks and constraints actually impeding and hampering the entrepreneurial response, on the other hand. The voluminous research identifying the emotional challenges and hazards limiting and deterring entrepreneurs highlighted in the second section of this paper is strikingly disconnected from the menu of policies and instruments used to spur entrepreneurship at all policy levels. It may be that entrepreneurs, or nascent (would-be) entrepreneurs, confronted with daunting emotional hazards may not endure, or even commence, upon the entrepreneurial journey (Aly and Galal-Edeen, 2020), even if policy provides them with the requisite funding, management capabilities, human resource management, marketing, accounting and technology related skills. These so-called hard skills may not always suffice to compensate for the negative impacts of emotional turmoil, stress and suffering, which lead entrepreneurs sometimes to give up on their ideas or suffer a serious self or social loss.

As the famous O-Ring theory, inspired by the Challenger disaster, tells us, that sometimes it is the weakest link that turns what otherwise would be success into failure (Kremer, 1993). So too it might be for entrepreneurship. To the extent that the emotional intelligence skills and emotional health of entrepreneurs have not been adequately addressed by public policy, if at all, emotional health and resilience may be the weakest link inhibiting entrepreneurs from fully succeeding along their entrepreneurial journey, let alone from starting out in the first place.

The entrepreneurship literature has found that one reason for the ineffectiveness of policy instruments in spurring entrepreneurial activity is a cultural context not conducive to entrepreneurship. Saxenian (1994) attributes the superior entrepreneurial performance of Silicon Valley viz-a-viz Route 128 around Boston to a difference in cultures. Similarly, Stuetzer et al (2016) show that the inability of regions in the North of England to generate entrepreneurship is attributed to a culture imprinted a century earlier that was decidedly hostile to entrepreneurship. By contrast, in the South of England, which had no such cultural imprint, entrepreneurship has flourished. Even more poignantly, Obschonka et al (2015) find that entrepreneurship policy only has traction as a catalyst to spur entrepreneurship in those regions in both the United States and the United Kingdom which have a culture conducive to entrepreneurship. Those regions with a culture not conducive to entrepreneurship exhibit a futility for public policy intervention to increase entrepreneurial activity. Since culture provides the context for the emotional response (Hofstede, 2001; Hofstede and McCrae, 2004), it follows that at least a part of creating a culture more conducive to entrepreneurship is an acceptance, understanding and nurturing of the emotional challenges inherent in the entrepreneurial journey.

While the urgent need and priority to equip entrepreneurs with the emotional intelligence and skills to thrive as they traverse the entrepreneurial journey has been flushed out and confirmed through rich and robust research, as Shepherd and Williams (2018) and 
Williamson (2021) point out, it remains to be translated into public policy providing instruments and solutions to foster emotional and mental resilience. The reluctance of policy to equip entrepreneurs with the emotional skills for entrepreneurial success may account for the wasted, or at least meager results, emanating from entrepreneurship policies in numerous contexts, spanning cities, regions, states and entire countries.

Thus, the inability for public policy to equip entrepreneurs with the skills for emotional resilience when confronting formidable emotional demands over their entrepreneurial journey reflects inadequate knowledge spillovers. In this case, the knowledge is the bounty harvested from the rich and robust research amassed in the entrepreneurship literature highlighting the daunting emotional challenges confronting entrepreneurs. The spillovers provide the conduit for the translation into actual clinical practices, programs and policies that positively impact and contribute to entrepreneurial success, and ultimately the success of their communities. When it comes to the emotional health of (would-be) entrepreneurs, the lack of knowledge spillovers to spawn the needed translational research represents a substantial loss in terms of forgone entrepreneurial success and ultimately economic vitality.

\section{Clinical view on future recommendations}

From a clinical perspective, the world needs public policy that enforces or supports regional or national cultural change to ignite entrepreneurship. Cultural change impacts the formula of both rapidity and type of economic development of societies as it forms the dynamics and the motives behind people's contribution to their societies' economic development and which level of entrepreneurial activity people are willing to accomplish (Geist \& Grimm, 2006). For example, residents of cities that are not conductive to entrepreneurship can learn to accept failure and celebrate if not encourage it, instead of being ashamed of it. Residents can learn to challenge the double-edged sword of perfectionism, and instead embrace the benefits of delegation. Such small, but essential steps may go a long way in transforming the underling culture of a city, region, state or even country, from impeding to igniting entrepreneurship. If entrepreneurs can nurture their emotions through positive growth, without the burden of feeling the fear, shame, guilt, ego, saving face, along with even more stressful emotions that are an everyday challenge along the entrepreneurial journey, the prospects accruing from entrepreneurship will be considerably enhanced.

Thus, the call here is for thought leaders in business and public policy not to ignore, but instead to nourish the human face of entrepreneurship. We look to public policy, broadly construed, to enable "the entrepreneurs" by prioritizing those remedial practices that equip entrepreneurs with the requisite tools and skills to become emotionally fit, as they confront the inevitable emotional rollercoaster along the entrepreneurial journey. By mitigating the emotional trauma suffered in the form of shame and guilt and ultimately driving them to abandon their ideas and entrepreneurial dreams by exiting the market, perhaps the number of failed entrepreneurs will be greatly reduced, if not the number of failed entrepreneurial ventures. Such emotional skills and tools resulting from therapeutic awareness and enhanced emotional intelligence can bolster their life balance, self-confidence, and relationships with their families, even as they create and grow their ventures, without succumbing to harmful egoistic or narcissistic behaviours.

Creating and adopting a new strategy that addresses cultural change through emotional awareness may become inevitable. Public policy and educational institutions should 
implement the type of education that helps people develop emotional intelligence, not just mental or logical-mathematical intelligence, which has been the default in entrepreneurial education. Guiding people to connect with their own emotions and learning how to manage them is the first step along the way to emotional intelligence and a high level of self-awareness.

This call for emotional skills for entrepreneurs is commensurate with the anticipated emergence of the fifth industrial revolution, which is poised at the cusp of our future. It calls for linking well-being and soft humanitarian factors with a myriad of technology, entrepreneurship, partnerships, innovation and quality of education, as well as advancing humanity at work places. ${ }^{9}$ When entrepreneurs or nascent (would-be) entrepreneurs grow more aware of their emotional connections to some cultural values and practices that are not serving their development and growth, they will be automatically able to question and alter the meanings underlying these cultural practices or values, become more flexible and take the step to change from within, in order to attain their entrepreneurial dreams.

"Lackeus (2015) developed and applied three categories of entrepreneurship education and training that are useful for a better understanding of how to teach public and policy entrepreneurship: education for, about, and through entrepreneurship. Whereas the first category highlights a very practical understanding and learning, the second category includes theoretical aspects and awareness education, and the third category goes beyond both other aspects by reflecting on entrepreneurial values and skills, problem-solving, conflict management, communication, etc. and is, therefore, also important for the education of future policy entrepreneurs. By turning to practical and real-life experiences, including role plays, participation in business idea competitions, and interaction with real world practitioners, the processes and challenges of entrepreneurial activity, as well as a capability for overcoming obstacles and reaching high goals, can be taught and enhances the development of an entrepreneurial mindset (Ramirez-Gonzalez, 2017; Grimm \& Boch, 2021).

To conclude, we recommend the following strategies:

1. Education: educating entrepreneurs emotionally to make them ready and well-equipped with the emotional fitness skills they need in their challenging entrepreneurial journey.

2. Clinical approaches: invite entrepreneurs and nascent entrepreneurs to invest in themselves, seeking clinical professionals to help them understand their emotional challenges and receive the proper emotional support.

3. Institutions: creating communities for entrepreneurial emotional support with specialized business psychology coaches to help entrepreneurs feel connected, rather than suffering loneliness and alienation during their entrepreneurial journey, as has analogously been applied to the concept of incubators, accelerators and business coaching.

4. Policy: transforming local/national/regional culture through altering the emotional metameanings and the belief system of the incubating social community in order to ignite an entrepreneurial culture within this community.

\footnotetext{
${ }_{9}$ World Economic Forum, May, 2019 after the United Nations Sustainable Development Goals (SDGs) for the Fifth Industrial Revolution: https://europeansting.com/2019/05/16/what-the-fifth-industrial-revolutionis-and-why-it-matters/.
} 


\section{Conclusions}

The world has awakened that it needs entrepreneurs. It needs entrepreneurs to harness new ideas, approaches and inject their energy and spirit, that can ultimately lift society up by addressing the problems, issues and needs that otherwise might go unnoticed and unattended. In the giddy rush to ignite entrepreneurship, a broad range of public and private policy approaches and instruments have been developed and implemented to bestow entrepreneurs with the requisite skills and resources for finance, management, accounting, marketing, human resources, and technological competency.

However, a growing body of research in the literature highlights the daunting emotional challenges confronting entrepreneurs as they traverse their entrepreneurial journey. While this research uncovering the links between emotions and entrepreneurs is central to understanding entrepreneurship, it has not been a catalyst for addressing the needs of entrepreneurs, either in the educational or clinical context. Even as the gap between research and actual improvements in the real world has been bridged for a broad range of challenges confronting entrepreneurs, there has been a glaring absence of translational research, along with the attendant educational and clinical applications, to enhance the emotional health of entrepreneurs.

This paper suggests how and why the paucity of translational research bolstering the emotional skills through education and training, as well as in clinical practice, has been a dis-service to entrepreneurs and would-be entrepreneurs. It has also been a dis-service to the cities, regions, provinces and entire countries that have looked to entrepreneurship as the means to ignite economic development and the overall standard of living. Public policy designed to spur entrepreneurship has often resulted in greater disappointment and frustration than actual entrepreneurial activity. This may be attributable less to the approaches and instruments comprising those policies and more to those that have been ignored and never implemented-in particular, policies and instruments to address the very real emotional challenges confronting entrepreneurs as they traverse across the entrepreneurial journey.

Ultimately, it may prove that the quest to ignite entrepreneurship through the highly coveted cultural transformation that sparks entrepreneurs will only be attained by recognizing and actively addressing their emotional needs and concerns. After all, history has taught us that if some of the most daunting problems confronting society can be solved through cultural change, certainly creating a cultural context addressing not just the financial and managerial needs of entrepreneurs but also the emotional challenges will go a long way in delivering the promise of entrepreneurship, upon which the hopes and dreams of so many rests.

\section{Funding Open Access funding enabled and organized by Projekt DEAL.}

Open Access This article is licensed under a Creative Commons Attribution 4.0 International License, which permits use, sharing, adaptation, distribution and reproduction in any medium or format, as long as you give appropriate credit to the original author(s) and the source, provide a link to the Creative Commons licence, and indicate if changes were made. The images or other third party material in this article are included in the article's Creative Commons licence, unless indicated otherwise in a credit line to the material. If material is not included in the article's Creative Commons licence and your intended use is not permitted by statutory regulation or exceeds the permitted use, you will need to obtain permission directly from the copyright holder. To view a copy of this licence, visit http://creativecommons.org/licenses/by/4.0/. 


\section{References}

Acs, Z., Åstebro, T., Audretsch, D., \& Robinson, D. T. (2016). Public policy to promote entrepreneurship: A call to arms. Small Business Economics, 47, 35-51.

Aldridge, T. T., \& Audretsch, D. B. (2011). The Bayh-Dole Act and scientist entrepreneurship. Research Policy, 40(8), 1058-1067.

Alvarez, S. S. (2005). Theories of entrepreneurship: Alternative assumptions and the study of entrepreneurial action. Foundations and Trends in Entrepreneurship.

Alvarez, S. S., \& Barney, J. B. (2007). The entrepreneurial theory of the firm. Journal of Management Studies, 44(7), 1057-1063.

Alvarez, S. S., \& Barney, J. B. (2005). How do entrepreneurs organize firms under conditions of uncertainty? Entrepreneurship Theory and Practice, 31(5), 776-793.

Aly, M., \& Galal-Edeen, G. (2020). Why is Germany less entrepreneurial? A behavioral reasoning perspective. Journal of Technology Transfer. https://doi.org/10.1007/s10961-020-09823-4

American Psychiatric Association. (2013). Diagnostic and statistical manual of mental disorders DSM5, 5th ed. American Psychiatric Association. https://doi.org/10.1176/appi.books.9780890425596

Antshel, K. M. (2018). Attention deficit/hyperactivity disorder (ADHD) and entrepreneurship. Academy of Management Perspectives, 32(2), 243-265.

Arrak, K., Kaasa, A., \& Varblane, U. (2020). Regional cultural context as a determinant of entrepreneurial behaviour: The case of Germany. The Journal of Entrepreneurship, 29(1), 88-118.

Audretsch, D. B. (2007). The entrepreneurial society. Oxford University Press.

Audretsch, D. B. (2015). Everything in its place: Entrepreneurship and the strategic management of cities, regions and countries. Oxford University Press.

Audretsch, D. B. (2017). Entrepreneurship in Germany. The Blackwell Handbook of Entrepreneurship (pp. 107-127).

Audretsch, D. B., Bönte, W., \& Keilbach, M. (2008). Entrepreneurship capital and its impact on knowledge diffusion and economic performance. Journal of Business Venturing, 23(6), 687-698.

Audretsch, D. B., Grimm, H., \& Wessner, C. W. (Eds.). (2005). Local heroes in the global village: Globalization the new entrepreneurship policies. Springer Publishers.

Audretsch, D. B., \& Keilbach, M. (2004). Does entrepreneurship capital matter? Entrepreneurship Theory and Practice, 66, 419-429.

Audretsch, D. B., Keilbach, M., \& Lehmann, E. E. (2006). Entrepreneurship and economic growth. Oxford University Press.

Audretsch, D. B., \& Lehmann, E. E. (2005). Does the knowledge spillover theory of entrepreneurship hold for regions? Research Policy, 34(8), 1191-1202.

Audretsch, D. B., \& Lehmann, E. E. (2016). The seven secrets of Germany: Economic resilience in an era of global turbulence. Oxford University Press.

Auerswald, P. E., \& Branscomb, L. M. (2003). Valleys of death and Darwinian Seas: Financing the invention to innovation transition in the United States. The Journal of Technology Transfer, 28, 227-239.

Baron, R. A. (2008). The role of affect in the entrepreneurial process. Academy of Management Review, $33,328-340$.

Baron, R. A., Hmieleski, K. M., \& Henry, R. A. (2012). Entrepreneurs' dispositional positive affect: The potential benefits-and potential costs—of being 'up.' Journal of Business Venturing, 27(3), 310-324.

Barrett, L. F., Mesquita, B., Ochsner, K. N., \& Gross, J. J. (2007). The experience of emotion. Annual Review of Psychology, 58, 373-403.

Baum, J. R., \& Locke, E. A. (2004). The relationship of entrepreneurial traits, skill, and motivation to subsequent venture growth. Journal of Applied Psychology, 89(4), 587-598.

Bernoster, I., Mukerjee, J., \& Thurik, R. (2018). The role of affect in entrepreneurial orientation. Small Business Economics, 54, 235-256.

Brandstätter, H. (2011). Personality aspects of entrepreneurship: A look at five meta-analyses. Personality and Individual Differences, 51(3), 222-230.

Bresnahan, T., \& Gambardella, A. (Eds.). (2004). Building high-tech clusters: Silicon valley and beyond. Cambridge University Press.

Breugst, N., Domurath, A., Patzelt, H., \& Klaukien, A. (2012). Perceptions of entrepreneurial passion and employees' commitment to entrepreneurial ventures. Entrepreneurship Theory and Practice, 36(1), 171-192.

Brockhaus, R. H. (2006). Risk tasking propensity of entrepreneurs. Academy of Management Journal. https://doi.org/10.5465/255515 
Bush, V. (1945). Science: The endless frontier. U.S. Government Printing Office.

Cacciotti, G., Hayton, J. C., James, C., Mitchell, J. R., \& Giazitzoglu, A. (2016). A reconceptualization of fear of failure in entrepreneurship. Journal of Business Venturing, 31(3), 302-325.

Calza, F., Cannavale, C., \& Nadali, I. Z. (2020). How do cultural values influence entrepreneurial behavior of nations? A behavioral reasoning approach. International Business Review, 29(5), 101725.

Cardon, M. S., Foo, M.-D., Shepherd, D., \& Wiklund, J. (2012). Exploring the heart: Entrepreneurial emotion is a hot topic. Entrepreneurship, Theory and Practice, 36(1), 1-10.

Cardon, M. S., Sudek, R., \& Mitteness, C. (2009a). The impact of perceived entrepreneurial passion on angel investing. In A. L. Zacharakis. (Ed.), Frontiers of entrepreneurship research, Proceedings of the Babson College Entrepreneurship Research conference (Babson College).

Cardon, M. S., Wincent, J., Singh, J., \& Drnovsek, M. (2009b). The nature and experience of entrepreneurial passion. Academy of Management Review, 34(3), 511-532.

Cardon, M. S., Zietsma, C., Saparito, P., Matherne, B., \& Davis, C. (2005). A tale of passion: New insights into entrepreneurship from a parenthood metaphor. Journal of Business Venturing, 20(1), 23-45.

Foo, M. (2011). Emotions and entrepreneurial opportunity evaluation. Entrepreneurship Theory and Practice, 35(2), 375-393.

Foo, M., Uy, M., \& Baron, R. A. (2009). How do feelings influence effort? An empirical study of entrepreneurs' affect and venture effort. Journal of Applied Psychology, 94(4), 1086-1094.

Geist, H. J., \& Grimm, H. M. (2006). Cultural Factors. In H. J. Geist (Ed.), The Earth's changing land: An encyclopedia of land-use/cover change (pp. 151-153). Greenwood Publishing Group.

Gilbert, B. A., Patricia, M., \& Audretsch, D. B. (2006). New venture growth: A review and extension. Journal of Management, 32(6), 926-950.

Gores, T., \& Link, A. N. (2021). The Globalization of the Bayh-Dole Act. Annals of Science and Technology Policy, 5(1), 1-90.

Grimm, H. (2004). assessment of entrepreneurship policies across nations and regions. In D. B. Audretsch, H. Grimm, \& C. W. Wessner (Eds.), 2005, Local heroes in the global village: Globalization the new entrepreneurship policies (pp. 145-169). Springer.

Grimm, H. (2006). Entrepreneurship policy and regional economic growth. In B. Rihoux, \& H. Grimm (Eds.), Innovative comparative methods for policy analysis (pp. 123-144). Springer.

Grimm, H. (2009). Creating an entrepreneurial economy: The role of public policy. In Z. J. Acs, D. B. Audretsch, \& R. Strom (Eds.), Entrepreneurship, growth and public policy (pp. 299-319). Cambridge University Press.

Grimm, H. (2011). The Lisbon agenda and entrepreneurship policy: Governance implications from a german perspective. Public Administration, 89(4), 1526-1545.

Grimm, H., \& Boch, C. L. (2021). Entrepreneurship in public administration and public policy programs in Germany and the United States. Teaching Public Administration. https://doi.org/10.1177/0144739421 1021636/ID:TPA-20-0054.R1

Hatak, I., Chang, M., Harms, R., \& Wiklund, R. J. (2020). ADHD symptoms, entrepreneurial passion, and entrepreneurial performance. Small Business Economics. https://doi.org/10.1007/ s11187-020-00397-x

Hofstede, G. (2001). Culture's consequences: Comparing values, behaviors, institutions and organizations across nations. Sage.

Hofstede, G., \& McCrae, R. R. (2004). Personality and culture revisited: Linking traits and dimensions of culture. Cross-Cultural Research, 38(1), 52-88.

Hülsbeck, M., \& Lehmann, E. E. (2007). Entrepreneurship policy in Bavaria: Between laptop and Lederhosen. In D. B. Audretsch, I. Grilo, \& A. R Thurik (Eds.), Handbook of research on entrepreneurship policy (pp. 200-212), Edward Elgar.

Hülsbeck, M., Lehmann, E. E., \& Starnecker, A. (2013). Performance of technology transfer offices in Germany. Journal of Technology Transfer, 38, 199-215.

Inglehart, R. (1997). Modernization and postmodernization in 43 societies (pp. 67-107). Princeton University Press.

Jang, K. L., Livesley, W., \& Vernom, P. A. (1996). Heritability of the Big Five personality dimensions and their facets: A twin study. Journal of Personality, 64(3), 577-592.

John, O. P., \& Srivastava, S. (1999). The Big Five trait taxonomy: History, measurement, and theoretical perspectives. In L. A. Pervin \& O. P. John (Eds.), Handbook of personality: Theory and research (2nd ed., pp. 102-138). Guilford.

Kaasa, A., Vadi, M., \& Varblane, U. (2014). Regional cultural differences within European countries: Evidence from multi-country surveys. Management International Review, 54(6), 825-852.

Kerr, S. P., Kerr, W. R., \& Dalton, M. (2019). Risk attitudes and personality traits of entrepreneurs and venture team members. Proceedings of the National Academy of Sciences, 116-36, 17712-17716. 
Knight, F. H. (1921). Risk, uncertainty, and profit. Hart, Scaffner \& Marx.

Koellinger, P. D., van der Loos, M. J., Groenen, P. J., Thurik, A. R., Rivadeneira, F., \& van Rooij, F. J. (2010). Genome-wide association studies in economics and entrepreneurship research: Promises and limitations. Small Business Economics, 35(1), 1-18.

Kremer, M. (1993). The O-Ring theory of economic development. Quarterly Journal of Economics, 108(3), $551-575$.

Lackeus, M. (2015). Entrepreneurship in education. What, why, when, how. Entrepreneurship360. Background Paper. OECD.

Landier, A. (2005). Entrepreneurship and the stigma of failure. Available at SSRN 850446.

Lehmann, E. E., \& Starnecker, A. (2012). Introducing the universities of applied sciences. In D. B. Audretsch, E. E. Lehmann, A. N. Link, \& A. Starnecker (Eds.), Technology transfer in a global economy. Springer.

Lerner, J. (2012). Boulevard of broken dreams: Why public efforts to boost entrepreneurship and venture capital have failed-and what to do about it. Princeton University Press.

Link, A. N. (1995). A generosity of spirit: The early history of the Research Triangle Park. Research Triangle Foundation of North Carolina.

Link, A. N., \& Scott, J. T. (2010). The government as entrepreneur: Evaluating the commercialization success of SBIR projects. Research Policy, 39(5), 589-601.

Link, A. N., \& Scott, J. T. (2012). Employment growth from the Small Business Innovation Research Program. Small Business Economics, 39, 265-287.

Loehlin, J. C., McCrae, R. R., Coast, P. T., Jr., \& John, O. P. (1998). Heritabilities of common and measure-specific components of the Big Five personality factors. Journal of Research in Personality, 32(4), 431-453.

Love, H. (2016). The start-up J Curve: The six steps to entrepreneurial success. Greenleaf Book Group Press.

Magnusson, D., \& Torestad, B. (1993). A holistic view of personality: A model revisited. Annual Review of Psychology, 44(1), 427-452.

McMullen, J., \& Shepherd, D. A. (2006). Entrepreneurial action and the role of uncertainty in the theory of the entrepreneur. Academy of Management Review, 31(1), 66.

Mitteness, C., Sudek, R., \& Cardon, M. S. (2012). Investor characteristics that determine whether perceived passion leads to higher evaluations of funding potential. Journal of Business Venturing, 27(5), 592-606.

Mowery, D., Nelson, R. R., Sampat, B., \& Ziedonis, A. (2004). Ivory Tower and Industrial Innovation: University-Industry Technology Transfer before and after the Bayh-Dole Act. Stanford University Press.

Obschonka, M., \& Stuetzer, M. (2017). Integrating psychological approaches to entrepreneurship: The Entrepreneurial Personality System (EPS). Small Business Economics, 49, 203-231.

Obschonka, M., Stuetzer, M., Gosling, S. D., Rentfrow, P. J., Lamb, M. E., Potter, J., \& Audretsch, D. B. (2015). Entrepreneurial regions: Do macro-psychological cultural characteristics of regions help solve the "knowledge-paradox" of economics? PLOS ONE, 10(6), e0129332.

Patzelt, H., \& Shepherd, D. A. (2011). Negative emotions of an entrepreneurial career: Self-employment and regulatory coping behaviors. Journal of Business Venturing, 26(2), 226-238.

Ramirez-Gonzalez, F. L. (2017). Entrepreneurship education and the promotion of small business. The case of Pilar, Paraguay. Master Thesis Submitted to the Willy Brandt School of Public Policy, University of Erfurt.

Rietveld, C. A., Slob, E. A., \& Thurik, A. R. (2020). A decade of research on the genetics of entrepreneurship: a review and view ahead. Small Business Economics. https://doi.org/10.1007/ s11187-020-00349-5

Saxenian, A. L. (1994). Regional advantage: Culture and competition in Silicon Valley and Route 128. Harvard University Press.

Senor, D., \& Singer, S. (2011). Start-up nation: The story of Israel's Economic Miracle. Twelve.

Shepherd, D. A. (2003). Learning from business failure: Propositions of grief recovery for the selfemployed. Academy of Management Review, 28(2), 66s.

Shepherd, D. A. (2004). Educating entrepreneurship students about emotion and learning from failure. Academy of Management Learning \& Education, 3(3), 274-287.

Shepherd, D. A. (2009). Grief recovery from family business failure: A multi- and meso-level theory. Journal of Business Venturing, 24(1), 81-97.

Shepherd, D. A. (2017). Educating entrepreneurship students about emotions and learning from failure. Academy of Management Learning \& Education, 3(3), 66. 
Shepherd, D. A., \& Williams, T. A. (2018). Hitting rock bottom after job loss: Bouncing back to create a new positive work identity. Academy of Management Review, 43(1), 28-49.

Shepherd, D., Patzelt, H. H., \& Wolfe, M. M. (2011). Moving forward from project failure: Negative emotions, affective commitment, and learning from the experience. Academy of Management Journal, 54(6), 361-380.

Shepherd, D., Wiklund, J., \& Haynie, J. (2009). Moving forward: Balancing the financial and emotional costs of business failure. Journal of Business Venturing, 24(2), 134-148.

Siegel, D. S., \& Link, A. N. (2005). University-based technology initiatives: Quantitative and qualitative evidence. Research Policy, 34(3), 253-325.

Siegel, D. S., Waldman, D., \& Link, A. (2003). Assessing the impact of organizational practices on the relative productivity of university technology transfer offices: An exploratory study. Research Policy, $32(1), 27-48$.

Simmons, S. A., Wiklund, J., \& Levie, J. (2014). Stigma and business failure: Implications for entrepreneurs' career choices. Small Business Economics, 42(3), 485-505.

Singla, D. R., Raviola, G., \& Patel, V. (2018). Scaling up psychological treatments for common mental disorders: A call to action. World Psychiatry, 17(2), 226-227.

Stokes, D. E. (1997). Pasteur's Quadrant-Basic science and technological innovation. Brookings Institution Press.

Stroe, S., Siren, C., Shepherd, D., \& Wincent, J. (2020). The dualistic regulatory effect of passion on the relationship between fear of failure and negative affect: Insights from facial expression analysis. Journal of Business Venturing, 3(4), 66.

Stuetzer, M., Audretsch, D. B., Obschonka, M., Gosling, S. D., Rentfrow, P. J., \& Potter, J. (2018). Entrepreneurship culture, knowledge spillovers and the growth of regions. Regional Studies, 52(5), 608-618.

Stuetzer, M., Obschonka, M., Audretsch, D. B., Wyrwich, M., Rentfrow, P. J., Coombes, M., Shaw-Taylor, L., \& Satchel, M. (2016). Industry structure, entrepreneurship, and culture: An empirical analysis using historical coalfields. European Economic Review, 86, 52-72.

Tavassoli, S., Obschonka, M., \& Audretsch, D. B. (2021). Entrepreneurship in Cities. Research Policy.

Ucbasaran, D., Shepherd, D. A., Lockett, A., \& Lyon, S. J. (2012). Life after business failure: The process and consequences of business failure for entrepreneurs. Entrepreneurship Theory and Practice, 39(1), $163-202$.

Ucbasaran, D., Shepherd, D. A., Lockett, A., \& Lyon, S. J. (2013). Life after business failure: The process and consequences of business failure for entrepreneurs. Journal of Management, 39(1), 163-202.

Welpe, I. M., Spörrle, M., Grichnik, D., Michl, T., \& Audretsch, D. B. (2012). Emotions and opportunities: The interplay of opportunity evaluation, fear, joy, and anger as antecedent of entrepreneurial exploitation. Entrepreneurship Theory and Practice, 36(1), 69-96.

Welter, F. (2011). Contextualizing entrepreneurship-Conceptual challenges and ways forward. Entrepreneurship Theory and Practice, 35(1), 165-184.

Welter, F., Baker, T., \& Wirsching, K. (2019). Three waves and counting: The rising tide of contextualization in entrepreneurship research. Small Business Economics, 52, 319-330.

Wessner, C. C. (Ed.). (2008). National Research Council: An assessment of the SBIR program. National Academies Press.

Williamson, A. J. (2021). Let's focus on solutions to entrepreneurial ill-being: Recovery interventions to enhance entrepreneurial well-being. Entrepreneurship Theory and Practice, 6, 66.

Williamson, A. J., Drencheva, A., \& Battisti, M. (2021). Entrepreneurial disappointment: Let down and breaking down, a machine-learning study. Entrepreneurship Theory and Practice. https://doi.org/10. $1177 / 1042258720964447$

Wolfe, M. T., \& Shepherd, D. A. (2015). Bouncing Back” from a loss: Entrepreneurial orientation, emotions, and failure narratives. Entrepreneurship Theory and Practice, 39(3), 675-700.

Zhao, H., \& Seibert, S. E. (2006). The Big Five personality dimensions and entrepreneurial status: A metaanalytical review. Journal of Applied Psychology, 91(2), 259-271.

Publisher's Note Springer Nature remains neutral with regard to jurisdictional claims in published maps and institutional affiliations. 